\title{
Las bolcheviques. Izquierda partidaria y movimiento de mujeres en la Argentina reciente
}

\author{
Natalia Casola \\ Universidad de Buenos Aires, Argentina - Consejo Nacional de Investigaciones Científicas y Técnicas - \\ Instituto Interdisciplinarios de Estudios de Género - \\ Centro de Estudios Históricos de los Trabajadores y las Izquierdas \\ nataliacasola@hotmail.com \\ ORCID: 0000-0003-2107-6840
}

Titulo: The Bolsheviks. Party left and women's movement in recent Argentina

Resumen: En los últimos años el interés por estudiar la historia del movimiento de mujeres y del feminismo en Argentina ha registrado un sensible crecimiento. Si bien se ha avanzado en el conocimiento sobre la experiencia de diversos colectivos, agrupamientos y demandas específicas, poco o nada se ha escrito sobre el papel de los partidos de izquierda en esos procesos, a pesar de que han estado presentes en la mayoría de las luchas. Este artículo se propone comenzar a resolver esa vacancia. Para ello propone una revisión panorámica acerca de las posiciones y formas de vinculación de cuatro partidos de izquierda (PC, PCR, MAS y PO) con el movimiento de mujeres.

Palabras clave: partidos de izquierda - movimiento de mujeres - feminismo Argentina

Abstract: In recent years, interest in studying the history of the women's movement and feminism in Argentina has grown significantly. Although there has been progress in understanding the experience of various groups, and specific

DOI: https://doi.org/10.46688/ahmoi.n19.328

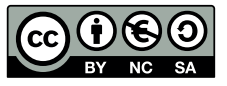

Obra bajo licencia Creative Commons 4.0 International (Atribución - NoComercial - Compartirlgual) 
demands, little or nothing has been written about the role of left-wing parties in these processes, despite the fact that they have been present in most of the struggles. This article aims to begin to resolve that vacancy. To do this, she proposes a panoramic review of the positions and forms of linkage of four left-wing parties (PC, PCR, MAS, and PO) with the women's movement.

Keywords: left parties - women's movement - feminism - Argentina

Recepción: 25 de marzo de 2021. Aceptación: 3 de julio de 2021

$* * *$

El presente artículo busca establecer cuándo y cómo la cuestión en torno de la opresión femenina comenzó a ser problematizada dentro de los partidos de izquierda en Argentina y qué políticas y prácticas militantes construyeron. "Mujeres", en el contexto de este trabajo, significa visibilizar sus luchas específicas y, por lo tanto, adoptar una perspectiva especial desde la cual reconsiderar las historias partidarias.

Este trabajo se centra en las experiencias del Partido Comunista (PC), el Partido Comunista Revolucionario (PCR), el Movimiento al Socialismo (MAS) y el Partido Obrero (PO), poniendo énfasis en el período posterior a 1983. Se trata de cuatro partidos con formas de organización similares, tributarios de la tradición leninista; esto es, la convicción en el papel director que debe cumplir el partido de la clase obrera en el proceso revolucionario, la constitución alrededor de un programa y la conformación de una estructura piramidal de cuadros profesionales regulada internamente por los mecanismos del centralismo democrático. A pesar de las profundas diferencias de estrategias y de las rivalidades existentes entre estalinistas, maoístas y trotskistas, esos elementos, sumados a la pertenencia común a una cultura de izquierda y la adscripción a un horizonte socialista como meta final, nos permite pensarlos en conjunto. ${ }^{1}$ Sin embargo, en el terreno de las reivindicaciones especificas de las mujeres observamos similitudes, pero también trayectorias distintas. Analizar esas diferencias significa reconocer el proceso histórico y, por tanto, dinámico de las definiciones sobre la opresión femenina, así como de las alteridades identitarias y la construcción de lazos de solidaridad en el marco de las alianzas con otras organizaciones de mujeres.

En Argentina, las reivindicaciones de las mujeres en los partidos de izquierda se expanden casi al mismo tiempo que se conforman la mayoría

1. En un futuro podría completarse el cuadro incorporando las experiencias del Partido Intransigente (PI), de importante gravitación en los años 80, y del Frente de Izquierda Popular (FIP), partido que, entre otras cosas, en 1983 impulsó la formación del primer Sindicato de Amas de Casa de la República Argentina (SACRA). 
de las agrupaciones feministas. ${ }^{2}$ Durante las décadas de 1980 y 1990 el diálogo con el feminismo se desarrolló atravesado por desconfianzas $\mathrm{y}$, también, por influencias recíprocas no siempre reconocidas como tales, pero que contribuyeron a conformar un movimiento de enorme radicalidad. Y si bien las tensiones eran patentes, lo que justifica la visión que pone de un lado al feminismo y del otro a la izquierda, lo cierto es que cada partido resolvió de modo diferente su vinculación con el movimiento de mujeres. Se intentará demostrar que tales diferencias reflejaban aspectos de sus estrategias politicas y de sus propias culturas partidarias.

Este artículo constituye una primera aproximación a un tema sobre el cual no hay investigaciones previas; incluso, salvo algunas excepciones, ni siquiera existe bibliografia suficiente sobre ninguno de los partidos en el período estudiado.

En la primera parte, se reconstruyen aspectos del contexto y se abordan los debates entre el feminismo y la izquierda partidaria poniendo el foco en los elementos comunes de la experiencia. Luego, se realiza un repaso por las trayectorias de cada partido enfatizando en sus particularidades. Para ello, se utilizan fuentes documentales tales como prensas partidarias, volantes y documentos congresales y entrevistas de historia oral que permiten confrontar, cruzar y pensar los puentes entre el pasado y el presente. ${ }^{3}$ Dado el carácter exploratorio del artículo y el acotado espacio, he decidido seleccionar solo algunas voces representativas, dejando afuera múltiples experiencias que, sin duda, contribuirán en el futuro a ofrecer un análisis de mayor complejidad.

\section{El movimiento de mujeres en ascenso. Feministas y marxistas}

Existe acuerdo en ubicar el ascenso del movimiento feminista en Argentina en la década de 1980, acompañado por el contexto de democratización y confianza en las reformas políticas como vía para construir una sociedad con mayor igualdad y equidad. Desde luego, las luchas de las mujeres no eran nuevas y se remontaban al siglo XIX. Una profusa bibliografia recorre sus luchas, con sus avances y retrocesos. Lo nove-

2. Dejamos explícitamente a un lado las militancias en los 70 porque su análisis requeriria otro espacio.

3. Este artículo fue escrito en medio de la pandemia de covid-19 con los archivos cerrados a la consulta pública. Me he valido de fuentes disponibles en internet, de mi archivo personal y de la generosidad de los y las colegas. Quedará para un futuro próximo una exploración más exhaustiva. Respecto de las entrevistas cabe resaltar que las mismas fueron realizadas en el contexto de la llamada "cuarta ola" del feminismo, la conformación del movimiento \#Ni una Menos y la aprobación de la Ley de Aborto Legal. 
doso de lo acontecido en los años 1980 fue que el movimiento feminista, con toda la batería de planteos propios de la llamada "segunda ola", consiguió una visibilidad pública inédita que logró, en articulación con las organizaciones de mujeres prexistentes, arrancar varias conquistas al Estado y poner en pie espacios de deliberación amplios, que devendrian centrales para entender su potencia política en la actualidad. ¿Quiénes eran las mujeres que capitanearon el cambio? Como varias investigaciones registraron, el feminismo de la década de 1980 se nutrió de experiencias distintas: a los minúsculos grupos de los años 1970 se unieron las militantes exiliadas que comenzaron a retornar al país y que habian tomado contacto con estas ideas en otras latitudes (Bellucci, 2014, p. 242; Franco, 2009). También confluyeron mujeres de los partidos políticos tradicionales y otras que en el decenio anterior habian participado de las organizaciones revolucionarias y que encontraron en el feminismo un espacio de intervención desde donde reconstruir sus militancias (Seminara y Viano, 2009).

Entre 1976 y 1983 las feministas habian logrado sostener un mínimo nivel de organización aglutinadas a partir de campañas específicas que aprovechaban las fisuras de la política propugnada por la dictadura militar sostenida en un discurso familiarista (Felitti, 2010; Grammático, 2019). La mayoría de las demandas no eran nuevas y recogian el legado de la década anterior. Sin embargo, ya en el contexto de la democratización y la expectativa en la capacidad de reforma de las instituciones, el feminismo comenzó a redireccionar su actividad en la demanda al Estado, sin abandonar la política de formación de grupos de concienciación, que había sido su principal acción en los años 1970 (Trebisacce, 2019). Ese cambio de orientación se manifestó en la ocupación del espacio público, acción que le permitió ganar mayor visibilidad y establecer acuerdos y alianzas con un arco político amplio, que no necesariamente se reconocía feminista. En ese marco, fueron varias las reivindicaciones que consiguieron un lugar en la agenda pública nacional: la reforma de la patria potestad, el derecho al divorcio vincular, la necesidad de establecer politicas orientadas a alcanzar la equidad entre varones y mujeres en las instituciones y la demanda de intervención más fuerte por parte del Estado para asistir la problemática de las mujeres.

Las novedades que introdujeron se abrieron camino en un contexto en el cual los principios de la sociedad patriarcal aun gozaban de buena salud. Si bien las demandas enunciadas en clave de democracia y derechos humanos aceitaban los debates y tendia puentes de diálogo, la presencia del feminismo todavía resultaba radical y perturbadora. Sus propuestas eran recibidas por muchas mujeres como un cuestionamiento a sus propias existencias como madres y esposas.

No obstante, la fortaleza que comenzaba a adquirir ese movimiento 
quedó plasmada, primero, en la conformación en diciembre de 1983 de la Multisectorial de la Mujer, un espacio donde convergian feministas, mujeres de los partidos políticos y sindicatos, y en la constitución de numerosos grupos, como ATEM 25, Lugar de Mujer, entre otros (Tarducci, 2019). A partir de 1986 comenzaron a organizarse los Encuentros Nacionales de Mujeres (ENM) que, con el paso de los años, devinieron en la principal instancia para el contacto amplio de las mujeres de todo el país y de todos los espacios políticos (Alma y Lorenzo, 2009). ${ }^{4}$

En ese contexto, de conformación y desarrollo del movimiento de mujeres, las militantes de los partidos de izquierda no quedaron al margen. Como había ocurrido en el pasado, el diálogo entre las feministas (en plural) y las marxistas (también en plural) discurría no sin tensiones. Si bien convergian en luchas callejeras, actos y manifestaciones, a la hora del debate solían mirarse con desconfianza y militar agendas paralelas.

Las feministas solían sospechar de todo acercamiento de las mujeres de los partidos como un intento de cooptación. En contraposición, solían organizarse a contrapelo de los modos jerárquicos que adoptaban y reivindicaban los partidos. Si bien muchas de las feministas no eran reacias al marxismo como tradición teórica, sí lo eran a las estructuras partidarias.

Como afirma Alicia Schejter, quien sostuvo una doble militancia en su condición de militante feminista en ATEM y militante socialista en el Partido Obrero: "en el feminismo leíamos autores marxistas. Leíamos a Engels o a las feministas marxistas. Había una crítica del capitalismo desde el feminismo, pero había una negación a los partidos, a las estructuras partidarias". ${ }^{5}$

Desde el punto de vista de los partidos de izquierda la cuestión planteaba diversos dilemas. A grandes rasgos, podría decirse que la polémica con las agrupaciones feministas se concentraba en torno de dos puntos: 1) si la especificidad de la opresión femenina justificaba un tipo de militancia separada o si, en cambio, contribuía a dividir a la clase trabajadora y 2) qué lugar debían ocupar las demandas de las mujeres como una totalidad en la agenda revolucionaria.

En este sentido, la izquierda de los años 1980 y 1990 fue permeable a los planteos del incipiente movimiento de mujeres, lo que puede interpretarse como un reconocimiento, no explicitado, de que el feminismo había logrado transformarse en una actriz política con incidencia. Sin embargo, siguió predominando una visión que sospechaba de toda

4. El primer encuentro de mujeres se gestó el 23 y 25 de mayo de 1986 en el Centro Cultural San Martín.

5. Entrevista a Alicia Schejter, febrero de 2021. Alicia fue militante del Partido Obrero desde 1982 y de ATEM desde 1984. 
reivindicación feminista como "burguesa", o "correa del imperialismo", epítetos que servian más para cancelar y archivar la discusión que para desarrollar una posición socialista. De igual modo, existía un fuerte temor al impacto que las reivindicaciones feministas podian tener en las filas obreras. Este temor al "divisionismo" los condujo, en ocasiones, a adoptar posturas conservadoras y evitar el abordaje de problemáticas no relacionadas directamente con el ámbito público y laboral. Podría decirse que la crítica a lo que hoy denominamos "sororidad" se tradujo en la resistencia a reconocer que al interior de la propia clase era necesario "ajustar cuentas". Aunque con notables diferencias entre organizaciones, continuó primando un enfoque que comprendía la opresión de clase como la madre de todas las otras formas de opresión, desconociendo, en algunos casos, los esfuerzos que las feministas marxistas en otras latitudes venian haciendo por pensar el problema.

Por consiguiente, cuando los partidos de izquierda elaboraban discursos dirigidos a las mujeres, estos apuntaban prioritariamente a las trabajadoras, pobres y excluidas, a la vez que no perdian oportunidad de remarcar las distancias que las separaba de las mujeres de la clase enemiga. Ciertamente no eran debates nuevos, pero se renovaban en un contexto de ampliación para la audibilidad de esta problemática.

Pero más allá de estos elementos en común que permiten agrupar a los partidos de izquierda dentro de una misma familia politica, considero que en las prácticas concretas del movimiento de mujeres existian diferencias. Como veremos a continuación, cada organización expresó, a su modo y siguiendo sus propias tradiciones partidarias, una manera de abordar la articulación entre partido y movimiento social y de resolver el contenido programático para orientar la actividad.

\section{El Partido Comunista}

La militancia comunista entre las mujeres tiene una larga historia que se remonta, por lo menos, a la década de 1930 y que le valió una experiencia que, al comenzar los años 80 , no tenía ningún otro partido de la izquierda. Desde 1947 la organización partidaria había seguido un modelo bifronte: por un lado, contaban con células femeninas coordinadas por una Comisión cuya principal función era el seguimiento en los sindicatos y, por otro, tenían una militancia territorial extendida por todo el país que era canalizada a través de la Unión de Mujeres Argentinas (UMA). ${ }^{6}$ Si bien desde el punto de vista estatutario la UMA

6. La UMA había sido fundada el 17 de julio de 1947, anteriormente habían formado parte de la Unión Argentina de Mujeres (UAM). Para un análisis de su militancia véase Valobra (2005) y Casola (2014). 
era una organización abierta — como lo eran todas las organizaciones de masas impulsadas por el PC — su conducción permaneció en manos del comunismo.

A lo largo del tiempo, las umistas había ido afinando sus propuestas y formas de dirigirse a las mujeres. Cuidadosas de no ahuyentarlas, sensibles a la existencia de prejuicios contra el comunismo, las mujeres de la UMA alentaban a las obreras y amas de casa a organizarse sin entrar en colisión con los idearios de feminidad y domesticidad predominantes. La apelación a la maternidad en términos políticos les permitía radicalizar los reclamos de las mujeres e interpelar al conjunto de la sociedad al poner en evidencia que las trabajadoras eran las más oprimidas. Desde el punto de vista de las alianzas, las mismas eran muy amplias en consonancia con los lineamientos del Frente Democrático Nacional o búsqueda de acuerdos con sectores considerados progresistas.

Durante la última dictadura militar, la UMA se transformó en un paraguas para numerosas militancias y a mediados de 1982 se erigió en la organización dirigente del movimiento de amas de casa que protagonizó las luchas contra los aumentos de precios. Gracias a esas protestas, en los años siguientes un conjunto de organizaciones de mujeres comenzó a estructurar el reclamo por salario y jubilación para las amas de casa.

A partir de 1984 y, sobre todo, desde 1986, la matriz "maternalista" comenzó a convivir con otra, en sintonía con la emergencia del feminismo en la arena pública. Comenzó a cuestionarse abiertamente la división sexual del trabajo y se incorporaron temáticas como la violencia machista, el aborto y el placer sexual. Hacia el final de la década adoptaron la categoría género y comenzaron a explicar la opresión femenina a partir de la existencia del patriarcado. ${ }^{7}$

El PC participó desde el inicio en los espacios de confluencia de agrupaciones de mujeres que, poco a poco, devenían en movimiento. Sin embargo, las tensiones con las lógicas del feminismo se manifestaron rápidamente. María Inés Brassesco,${ }^{8}$ por entonces responsable de la Comisión Femenina del PC, ilustra algunos aspectos de tales tensiones:

\footnotetext{
N.C.: ¿Participaron desde el Primer Encuentro Nacional de Mujeres?

M.I. B: Participé en nombre del Partido porque yo todavía estaba en la Comisión Femenina. [...] Fue un buen encuentro, pero creo que su gran defecto fue que eran mujeres fuera de
}

7. Aquí Nosotras, n¹05, mayo-julio de 1990.

8. María Inés Brassesco comenzó su militancia en el PCA en 1969. Fue delegada textil y se destacó tanto en el ámbito sindical como barrial en La Matanza. Desde 1985 tomó la tarea de reorganizar la militancia comunista en el frente de mujeres. 
sus estructuras de partidos politicos, sindicatos, incluso fuera de su ubicación de clase. Y no estuvieron muy democráticas porque el partido invitó a toda una delegación de cubanas, que era todo un homenaje que estuvieran las cubanas, y no las dejaron subir. Y en eso siempre fui audaz y las subí de prepo. Es que eran las copetudas que cuando querian un viaje a Unión Soviética te venían a hablar, pero después hacían estas cosas. ${ }^{9}$

Como puede verse, aparece en el relato la idea de que el feminismo por su propia concepción, su interpelación a todas las mujeres sin distinción política ni de clase, de alguna manera eclipsaba marcaciones que eran centrales para la politica de la izquierda. En su relato, al llamarlas "copetudas", reproduce una simplificación muy propia del contexto, respecto del feminismo como "burgués", sin distinguir grupos y vertientes. De igual modo, resulta interesante que en su enunciación admite prácticas que separaban al feminismo de la izquierda: "las subí de prepo", "siempre fui audaz", remite a lógicas de imposición que eran, justamente, uno de los puntos que levantaban una barrera entre unas y otras.

Y fuimos al segundo [Encuentro], después vino Rosario que fue el más grande. [...] Pero hubo manifestaciones muy jodidas. Nosotras fuimos en tres colectivos, no, en esa época se viajaba en tren y en tres vagones estaba lleno de mujeres que iban con la UMA, el grueso era UMA de los barrios y muy pobres, con sus hijos, y entonces las feministas empezaron a criticarlas porque cambiaban a los pibes, y después, viste, qué se yo, a las dirigentes les daban los hoteles y a la gente pobre las mandaban a las escuelas. ${ }^{10}$

Es poco probable que movilizaran la cantidad de compañeras que afirma si consideramos que para 1989 los ENM aun tenían dimensiones pequeñas. También es llamativo el señalamiento respecto a la existencia de prejuicios sobre las mujeres pobres cuando, precisamente, el Encuentro de Rosario inauguró la guardería "Así crecemos" para colaborar con las mujeres que viajaban juntos a sus hijos e hijas (Alma y Lorenzo, 2009, p. 61). Justamente por eso, lo que importa destacar del relato es hasta qué punto existía desconfianza hacia las feministas caracterizadas como mujeres burguesas desinteresadas por los problemas de las clases populares.

Pese a las diferencias enunciadas por María Inés Brassesco, que

9. Entrevista a María Inés Brassesco, noviembre de 2018.

10. Ibídem. 
luego pasaría a militar directamente en la UMA junto a otras destacadas militantes como Angélica Mendoza y Clara de Franco, el discurso del PC en la década del 80 se modernizó notablemente, lo cual puede atribuirse al intercambio con el feminismo y a la agenda sostenida en los Encuentros Nacionales de Mujeres.

Sin embargo, la transformación de la UMA no se debía únicamente al contacto con el feminismo. Dentro del partido, existía un clima adecuado para la reformulación de ideas. El XVI Congreso de 1986 había marcado el inicio del llamado "viraje revolucionario" que, entre otras cosas, sostenía la necesidad de "revolucionar" a la UMA porque entendía que su política se movia excesivamente en el campo del reformismo. Para ello reorganizó las funciones de la Comisión Femenina buscando que tuviera mayor influjo sobre la UMA. Entre otras cosas, se indicaba abandonar el arco de alianzas que tradicionalmente habian cimentado para acercar a otras mujeres de la izquierda, en consonancia con la política de Frente de Liberación Nacional y Social. Esa orientación desató un proceso muy conflictivo porque entraba en colisión con las umistas que no eran militantes del PC y con las comunistas que lo sentian como una intervención a sus militancias. De acuerdo con Brassesco, los dirigentes del partido, antes de reorganizar el trabajo hacia las mujeres, ya esperaban que pudiera generar conflictos con la UMA:

Una de las primeras conversaciones que tengo con Julio Pereyra -que no era mal tipo, pero era patriarcal- entonces dice: "mirá María Inés, nosotros cambiamos la Comisión Femenina porque dentro de poco hay que ver qué se hace con la UMA, porque es reformista [...], porque éstas dentro de poco nos piden anticonceptivos". ${ }^{11}$

La referencia a los anticonceptivos es evocada como expresión de los reparos que tenía el partido respecto del avance de las ideas feministas. Inversamente, la adopción de la perspectiva de género invitaba a las militantes a pensar la opresión de las mujeres al interior de la propia clase y del propio partido, subvirtiendo el mantra de no dividir a los trabajadores. ${ }^{12}$ Ese proceso de confrontación, condujo a la autonomización total de la UMA en 1992. Aqui Nosotras, en una nota firmada por Nuria Pérez Jacky, anunciaba el alejamiento en un tono que no ocultaba la hondura del conflicto.

11. Ibídem.

12. "Hacia dónde va el movimiento de mujeres", Aquí Nosotras, n 105 , mayo-julio de 1990, pp. 14-15. 
La autonomía que propone la UMA se compatibiliza con la necesidad de un referente político en cuya articulación no se apueste al utilitarismo táctico del Movimiento. Su discurso va develando la retícula que oculta y reproduce la segunda posición de la mujer en los partidos políticos de pertenencia; se hace visible el poder, como segmento particularmente recortado para ella, y la contradicción entre el potencial de su práctica concreta y su escasa participación en lugares de decisión. ${ }^{13}$

La crítica era furibunda. Se acusaba al PC y, en rigor, al conjunto de los partidos de hacer un uso instrumental de las demandas de las mujeres, mientras internamente mantenían formas de desigualdad. Sin embargo, es probable que las críticas fueran expresión de un desacuerdo mayor con la evolución de la política de partido.

Pese a todo, en los años 90 muchas militantes comunistas continuaron organizándose en el marco de la UMA. La inercia, los lazos afectivos y cierta desorganización interna en el partido pueden ayudar a comprender por qué volvían a la organización primaria. A mediados de esa década el PC fundó la Cátedra Libre de Estudios de Género como una manera de reorganizar su trabajo luego de la ruptura de la UMA.

\section{El Partido Comunista Revolucionario (PCR)}

La "cuestión de la mujer", como se la denominaba entonces, fue formalmente reconocida por el PCR en el año 1972, en el marco de su II Congreso. Desde entonces, existieron células femeninas coordinadas por una comisión a cargo de Clelia Íscaro. El objetivo fundamental era organizar a las trabajadoras tanto en el campo como en la ciudad. Diez años más tarde, en octubre de 1982, en el contexto de las luchas de las amas de casa contra los aumentos de precios, impulsaron la conformación de Amas de Casa del País (ACP), una agrupación plural desde el punto de vista partidario, pero que con el tiempo quedó identificada con el PCR. ${ }^{14} \mathrm{Su}$ constitución, en el contexto del declive de la dictadura militar, fue importante porque contribuyó a visibilizar el rol de las amas de casa en cuanto trabajadoras no remuneradas, permitió retomar los debates sobre el salario doméstico que se habían dado en los años 1970 y organizar una campaña alrededor de salario y jubilación. El enfoque hacia la problemática de las mujeres heredaba el modelo organizativo del PC: conformación de células femeninas para el seguimiento del

13. "UMA, una mirada ideológica”, Aquí Nosotras, n 108, septiembre de 1992, p. 19. 14. "No compre los jueves", Nueva Hora, n 384, 1 de octubre de 1982. 
mundo del trabajo y la construcción de una organización de masas y politicamente plural para trabajar en los barrios.

Amas de Casa se ajustaba a la línea del PCR que afirmaba que la revolución en Argentina debía ser democrática-popular, agraria y antiimperialista en marcha ininterrumpida al socialismo, lo que suponia la construcción de frentes de lucha con criterio de amplitud. Este enfoque, llevado a la lucha territorial encarada directamente por ACP explica que hubiera presencia de radicales y posteriormente, también, de peronistas en sus filas. De acuerdo con la actual dirigenta Laura Delmonte:

Amas de Casa expresaba la línea que estábamos buscando, de unidad en un frente único con otras mujeres que no eran comunistas revolucionarias, que tenían otro perfil entendiendo que la opresión es lo común. ${ }^{15}$

El planteo de Amas de Casa interpelaba especialmente a las mujeres de los barrios populares y lo hacía buscando politizar los roles tradicionales vinculados al trabajo doméstico.

El PCR no se consideraba feminista, y sostenía, como otros partidos de izquierda, que la lucha de las mujeres debia integrarse en un combate revolucionario que tenía como sujeto al proletariado. Sin embargo, esta visión inicialmente aditiva, en el sentido de sumar a las mujeres como aporte a un gran frente de lucha, también se expresaba como temor a dividir a la clase trabajadora, lo cual, en ocasiones, se tradujo en la justificación de ciertas conductas machistas. Se trataba de reparos que atravesaban a todas las organizaciones de izquierdas y que ayudan a explicar por qué algunas problemáticas fueron incorporadas más tardíamente. Por ejemplo, Rosa Nassif, una de las dirigentas más reconocidas del PCR, rememora los reparos que existían dentro del partido para problematizar las violencias machistas de los propios militantes varones.

Se planteaba si era correcto que una compañera dijera en la asamblea que su marido la golpeaba, porque eso podía dividir el movimiento, cómo se iba a decir eso si incluso podía ser un dirigente el golpeador. Se logró ganar a la dirección del movimiento y a Juan Carlos Alderete para que las compañeras pudieran plantear en las asambleas que eran golpeadas. [...] Por primera vez en la Escuela Amarilla pusieron un cartel

15. Entrevista en línea a Laura Delmonte, septiembre de 2020. Se incorporó al PCR en Rosario durante la última dictadura militar. Es psicóloga social y milita en el frente de mujeres desde la década de 1980. 
que dice "el compañero que golpea a una compañera no es un compañero". ${ }^{16}$

En el abordaje de tales violencias fue fundamental el aporte de las psicólogas sociales, una profesión en la que el PCR tenía tradición. María Conti, quien fuera secretaria de la sede porteña de la Escuela Pichon Rivière y miembro de la Comisión Nacional de Mujeres del partido, cumplió un papel fundamental en la incorporación de la problemática al interior del partido y luego en la Corriente Clasista y Combativa (CCC).

Con relación al movimiento de mujeres que comenzaba a cobrar forma en la transición democrática, el PCR participó activamente en su constitución. En las jornadas relacionadas con la conmemoración del 8 de marzo desde 1984 sostuvo presencia en el marco de la Multisectorial y muy tempranamente fueron receptivos a los espacios que se abrían alrededor de las iniciativas del feminismo y sus vinculos internacionales. En 1985 viajaron a Nairobi para participar del Congreso Mundial de las Mujeres y, al regresar, se integraron a la comisión encargada de organizar el Primer Encuentro de Mujeres en 1986.

Y comenzaron a funcionar los encuentros, y nuestra principal alianza fue con el feminismo tradicional... Alianza en unidad y lucha, por supuesto, porque en ese momento estaba muy agudizada esta cuestión de la "práctica política" o la "práctica del feminismo" entonces había debates muy profundos, el feminismo hizo todo un camino en politizarse y ya no podemos hablar del feminismo burgués como única línea, como era en ese debate. ${ }^{17}$

Esa participación temprana en los ENM le permitió al PCR ocupar rápidamente una posición estratégica dentro de las comisiones organizadoras. A diferencia de otros partidos de izquierda, desde el inicio defendieron el carácter deliberativo pero no resolutivo de los ENM en función de sostener la amplitud política. Esta posición le valió la confrontación tanto con el feminismo como con el resto de la izquierda al defender la posibilidad de que las mujeres católicas se expresaran dentro del Encuentro. Al respecto, mientras el partido defendía el aborto legal y lo integraba en su programa político, no ocurría lo mismo en las organizaciones territoriales porque disputaban las bases directamente con las mujeres católicas (Viano, 2014, p. 59).

16. "Las raíces históricas y los debates actuales en el movimiento de mujeres y feminista”, charla virtual a cargo de Rosa L. Nassif, organizada por el Partido del Trabajo y del Pueblo de Córdoba el 7 de agosto de 2020.

17. Entrevista a Laura Delmonte. 
A partir de 1994, la formación de la Corriente Clasista y Combativa (CCC) transformó la militancia del PCR y afianzó el trabajo con las mujeres sobre todo en los barrios más humildes. Desde entonces, el PCR comenzó a movilizar masivamente a los ENM. Como ocurría también en otros partidos, los Encuentros funcionaban como el pivote alrededor del cual giraba gran parte de la actividad anual. ACP, la construcción del Movimiento de Mujeres de la CCC y la apertura de las llamadas Casas de la Mujer para atender la problemática de la violencia fueron los puntales para afianzar esa militancia, sobre todo en el interior del país.

\section{El Movimiento al Socialismo}

La reflexión en torno de la opresión femenina estuvo presente tempranamente en la corriente morenista. Como han demostrado Trebisacce y Mangiantini (2015), las ideas feministas ingresaron en el PST a inicios de la década del 70 por influencia del Socialist Workers Party (SWP) de Estados Unidos. La novedad respecto de cualquier otro abordaje realizado por la izquierda de la época radicaba en el reconocimiento de los elementos subjetivos y de las relaciones interpersonales como significativos para explicar la situación subordinada de las mujeres. Pese a ello, existía dificultad para encontrar un equilibrio entre las propuestas del feminismo, trasversales a todas las mujeres, y la centralidad de la cuestión de clase, que tendía a regresarlos a interpelar exclusivamente a las mujeres trabajadoras. Esa tensión fue arrastrada en la década siguiente.

Durante la dictadura militar los debates en torno de la cuestión de la mujer ganaron precisión y mayor densidad teórica. En 1979, durante el exilio colombiano, país donde se encontraba el núcleo dirigente, se elaboró un documento firmado por Mercedes Petit y Carmen Carrasco titulado "Mujeres trabajadoras y marxismo". Este escrito definió la orientación oficial del PST, y luego del MAS, respecto de la temática. En él se afirmaba que "las tareas de la liberación de las mujeres como tales son democrático-burguesas, históricamente se plantean con el comienzo del capitalismo y pertenecen a todas las clases". De esta caracterización se desprendía la necesidad de acompañar esas luchas en su conjunto, sin perder de vista que: "ninguna lucha democrática [...] va objetivamente contra el capitalismo [...] pueden adquirir una dinámica anticapitalista [...] [pero] dependerá de su contexto, programa y dirección" La conclusión era acompañar la lucha de todas las mujeres, pero con un programa clasista dirigido a las trabajadoras "para movilizarlas hacia la toma del poder" (Carrasco y Petit, 1979), lo cual, en la práctica, inevitablemente, las haría entrar en colisión con la perspectiva del feminismo independiente. 
En 1982 el PST cambió su nombre y fue renombrado como Movimiento al Socialismo (MAS) para sortear la proscripción y conseguir la legalidad necesaria para presentarse a elecciones. Durante la campaña electoral las demandas de las mujeres estuvieron muy presentes comenzando por la fórmula electoral que llevó a Luis Zamora y Silvia Díaz como candidatos a la presidencia y vicepresidencia, respectivamente. En aquellos meses prácticamente en todos los barrios los volantes del MAS hacian referencia a las mujeres que llevaban en sus listas buscando, explícitamente, interpelar a las amas de casa y trabajadoras: "Vote por un medio salario por hijo menor de 18 años y por el derecho al divorcio", ${ }^{18}$ "Vecina: asegure con su voto la presencia de una mujer luchadora en el municipio", ${ }^{19}$ entre otras consignas a tono. Aunque en el fragor de la reorganización partidaria la Comisión Femenina había dejado de funcionar, las reivindicaciones específicas de las mujeres estaban completamente integradas al trabajo del partido y, aun con limites, posibilitaba el ejercicio autorreflexivo sobre el tema.

Con la recuperación de la democracia, la celebración del 8 de marzo quedó incorporada al calendario de conmemoraciones de lucha. Ya hemos dicho que la jornada de 1984 fue central para la constitución del movimiento de mujeres. En aquel año fue la Multisectorial la que logró mayor convocatoria en la Plaza de los dos Congresos. En esa ocasión, sin embargo, el MAS no adhirió a esa marcha y en cambio se sumó a una jornada en Plaza de Mayo convocada por artistas en homenaje a las Madres de Plaza Mayo. Desde entonces, todos los años el partido comenzó a organizar la conmemoración del 8 de marzo alrededor de actividades propias que se desarrollaban en los distintos locales.

La cuestión volvió a adquirir mayor organicidad a partir de 1986, luego del primer Encuentro Nacional de Mujeres. El MAS participó con una pequeña delegación que, junto con el PC en el marco del Frente del Pueblo, impulsó la organización de un Encuentro Nacional de Mujeres Trabajadoras (ENMT) que finalmente se realizó en marzo del año siguiente. De cara a los preparativos de ese Encuentro, el MAS volvió a reunir a la Comisión Femenina y a editar un boletín específico con el nombre "Mujeres", para darle mayor sistematicidad y contenido a la participación. Ese año las actividades fueron muy numerosas y las tuvieron como protagonistas en la Comisión Promotora del ENMT. Resulta interesante reconstruir los vericuetos de la realización de este encuentro de mujeres con eje en las trabajadoras, porque permite analizar gran parte de las tensiones presentes en el movimiento de mujeres; por un lado, habian sido las feministas quienes más habian impulsado la rea-

18. Volante "A la mujer trabajadora", octubre de 1983.

19. Volante del barrio Lago del Bosque, octubre de 1983 
lización del primer ENM; pero inmediatamente tanto el arco partidario como el sindical se hicieron eco de ese espacio para replicarlo a su manera y con sus modos, muchos de los cuales alimentaban los reparos de las feministas cuando acusaban a las "politicas" de "aparatear". ${ }^{20}$

Desde entonces, el MAS participó de todos los ENM focalizando su intervención en los talleres vinculados, sobre todo, a trabajo y sindicalismo. Asimismo, alentó la conformación de comisiones de mujeres en los cuerpos de delegados de los sindicatos donde tenían presencia y pugnó por la incorporación de reclamos específicos.

Quizás la mayor originalidad la tuvieron en el plano del movimiento por los derechos de las disidencias sexuales y la conformación de grupos de la corriente Alternativa Socialista por la Liberación Sexual (Bellucci, 2020, pp. 52-59). Esta experiencia merece un análisis específico porque, puesta en contexto, muestra una radicalidad que no tuvo ninguna otra organización de la izquierda, y que, en algunos casos, tampoco tenían las organizaciones feministas cuando solian rehuir a la cuestión del lesbianismo. Desde luego, la conformación de esta corriente no expresaba necesariamente que el conjunto del partido abrazara esta política, pero sí muestra que al menos formalmente el MAS era receptivo a incorporar demandas de sectores que eran marginados socialmente a causa de su orientación sexual.

Sin embargo, los límites de esa libertad de organización se manifestaban en una cantidad de prejuicios sostenidos en la supuesta necesidad de no "espantar a la clase obrera". Nora Ciapponi, una de las referentes más reconocidas del MAS recuerda:

Mirá, $[\ldots]$ como no existía un debate al respecto de forma permanente, los prejuicios existian. O sea, yo conozco varios compañeros que las mismas compañeras de sus lugares de militancia le buscaban novia a un compañero que claramente era gay, entonces todo eso los llevaba de alguna manera a esconder su sexualidad. Todo eso tuvo sus contradicciones y en la posdictadura, con todo lo que traía la dictadura de prejuicios y de toda la importancia de que se hacía más ideología que política real, y que como la clase obrera rechazaba, "había que ser cuidadoso", todos esos prejuicios se tuvieron como parte de las contradicciones que la misma organización tenía... ${ }^{21}$

Esta anécdota muestra cierta adaptación del partido a las posiciones

20. Circular interna $n^{\circ} 156,7$ de octubre de 1986 .

21. Entrevista a Nora Ciapponi, septiembre de 2020. Militante del PST desde su formación. Entre otras cosas, fue candidata a vicepresidenta en 1973. 
más conservadoras por temor a quedar aislados respecto de los trabajadores. En cierto sentido, las reivindicaciones de las mujeres eran mucho más fáciles de sostener cuando transitaban lugares ya legitimados: reclamos para proteger a las madres trabajadoras, para conseguir mayor paridad en los sindicatos o cualquier otra medida que, de paso, coadyuvaba con la finalidad del partido de reclutar nuevos militantes.

Yo cuando volví de estar afuera [...] quería ir a una regional [...] Y elijo San Martin, Tres de Febrero y ahí al poco tiempo [...] tenía la regional llena de personas de distintas sexualidades. Es decir que se iban a pasando el dato de que en esta regional iban a estar tranquilos. Con total desprejuicio se fue logrando que los temas de sexualidad también se discutiesen con los obreros. [...] Y todo eso se pudo hacer demostrando que el prejuicio estaba en nosotros y no en la clase obrera. Había que explicar que esto es así y nada más. ${ }^{22}$

Para analizar el MAS debe tomarse en cuenta que entre 1988 y en 1992 se produjeron rupturas y fraccionamientos. La cuestión sobre la organización de las mujeres, entonces, vuelve a reaparecer durante los años 1990 ya bajo otras denominaciones políticas, además del propio MAS: el Partido de los Trabajadores Socialistas (PTS) y el Movimiento Socialista de los Trabajadores (MST), partidos nuevos que, a pesar de los balances críticos, heredaron la sensibilidad hacia la problemática de las mujeres y las disidencias.

\section{El Partido Obrero}

El primer nombre del Partido Obrero fue Política Obrera. Debió renombrase en 1982 para poder conseguir la legalidad partidaria y presentarse a elecciones sorteando los decretos de proscripción que la dictadura mantuvo vigentes hasta el final.

Al igual que el PST, también consideraba que la clase obrera era el sujeto prioritario de la revolución socialista. Por tanto, la principal tarea del partido era crecer en su seno, proponiendo un programa que trabajara por reivindicaciones inmediatas, pero sin perder de vista su necesaria articulación con un programa máximo. Esta caracterización los llevará por mucho tiempo a estructurar un trabajo político fundamentalmente en el frente universitario, el fabril y posteriormente el barrial.

Con relación a la problemática de las mujeres, el PO fue el partido de izquierda que más tardiamente comenzó a abordarla. Salvo algunas referencias esporádicas, entre 1964 y 1993 no existió reflexión siste-

22. Ibídem. 
mática al respecto. En los años 1970 sostuvieron reivindicaciones como el derecho al aborto legal y la protección a la maternidad, pero que no iban acompañadas de mayor producción teórica ni acciones concretas. ${ }^{23}$ Tampoco las mujeres militantes instalaron esos debates. La agenda política de la organización estaba pautada en torno de otros debates y la cuestión de la mujer no fue abordada teóricamente. Podría pensarse que existía una autorrepresentación de igualdad que funcionaba como un bloqueo para pensar la cuestión feminista en su interior. De alguna manera, aquella militancia revolucionaria de los 70 puede pensarse como la forma preponderante que cobró la ruptura femenina con los roles tradicionales (Vasallo, 2009).

A partir de 1983 el contexto comenzó a presentar modificaciones acompañado de la irrupción pública del feminismo. En 1984 el PO participó en la Multisectorial de Mujeres que organizó la primera manifestación pública por el 8 de marzo, pero en los siguientes años las demandas específicas volvieron a desaparecer de la agenda política del partido. Las acciones más cercanas fueron el apoyo y participación en las movilizaciones por la ley de divorcio vincular y la campaña sostenida por la liberación de la presa política Hilda Nava de Cuesta, ambas cuestiones abordadas desde lo que el partido denominaba como "libertades democráticas".

El debate en torno de la "cuestión de la mujer" irrumpió recién en 1993. Desde entonces, se inició una etapa de construcción de una línea de intervención propia para el movimiento de mujeres que culminó en 1998 con la creación del Plenario Autoconvocado de Trabajadoras (PdT).

El puntapié inicial lo dio una militante de Tucumán, Lucía Ferreira, cuando envió al correo de lectores de Prensa Obrera un informe muy pormenorizado donde reivindicaba las dinámicas y los contenidos de los Encuentros Nacionales de Mujeres y criticaba al partido por la poca atención y hasta la subestimación que hacía de los mismos. ${ }^{24}$ Número tras número, esta sección del periódico se fue poblando de voces que escribían para opinar sobre el tema, lo que muestra hasta qué punto el informe había tocado una fibra sensible en las filas militantes. Finalmente, la cuestión saltó a las páginas centrales de la prensa partidaria lo que denotaba que la dirección del PO había resuelto sentar una posición oficial sobre el tema. En aquel escrito, el dirigente Daniel Blanco afirmaba que existía una doble opresión de la mujer, como trabajadora y como esclava del hogar. Pero, luego, repetía (e interpretaba) lo que

23. "El Papa, la píldora y la familia", Politica Obrera, 2 de septiembre de 1968; "E1 aborto: un derecho democrático", "Ser madre soltera ¿también se reprime?" y "Discriminación laboral”, Nueva Generación, n 6, junio de 1980, pp. 17-18.

24. "Sobre el VIII Encuentro Nacional de Mujeres", Prensa Obrera, 6 de julio de 1993, p. 8. 
Engels había escrito respecto a cómo las relaciones capitalistas tenían como involuntaria virtud socavar la estricta división del trabajo sexual. Sin embargo, al no reconocer que justamente esa esclavitud doméstica era ejercida por varones, desdibujaba la especificidad de la opresión femenina. La cuestión volvía a remitirse a que la liberación de la mujer:

solo se logrará con la abolición de clases [...] y cuando el nivel de las fuerzas productivas haya alcanzado un grado tal de desarrollo que permita que el conjunto de las tareas económicas de las familias que esclavizan a la mujer sea absorbidas por la sociedad socialista.

Luego remataba:

sostenemos que no existe una cuestión estrictamente femenina y que las reivindicaciones de la mujer se deben unir con la lucha de los demás explotados, en contra de los explotadores de ambos sexos.

Respecto del feminismo, Blanco afirmaba:

El PO debe desenmascarar el contenido burgués de estos movimientos y sus limitaciones insalvables para alcanzar la liberación de la mujer dentro del marco capitalista, denunciando además que su política de división de los explotados solo puede favorecer a la dominación burguesa de la sociedad. ${ }^{25}$

No obstante, la nota, al mismo tiempo que ponía palabras a la delimitación con el feminismo, abría una fisura: afirmaba que la política hacia la mujer debía ser incorporada como debate del VI Congreso del partido y sugería votar un plan de acción que debía incluir "la creación de una Comisión Central encargada del trabajo sobre la mujer. ${ }^{26}$

Este cambio, no del todo reconocido como tal, nos permite mostrar que el crecimiento del movimiento de mujeres y del feminismo lograba permear a los partidos políticos llevando los debates al interior de las organizaciones.

Desde entonces, el PO se dio a la tarea de intervenir en los ENM, pero con la línea de delimitación del "feminismo burgués" y de crítica a los métodos de deliberación sin instancias resolutivas. Asimismo, fue tomando fisonomía una lectura que criticaba la caracterización de

25. "Sobre el movimiento de liberación de la mujer", Prensa Obrera, 10 de noviembre de 1993, pp. 8 y 9.

26. "Bases para una política revolucionaria", Prensa Obrera, 24 de noviembre de 1993. 
la mujer como una totalidad oprimida. En su lugar, se hacía hincapié exclusivamente en las trabajadoras.

Como hemos dicho anteriormente, el rechazo a pensar la opresión de las mujeres en su conjunto les impedía reconocer el sexismo como un componente que al interior de la propia clase funcionaba como un elemento de desigualdad. Entre las mujeres, todavía predominaba la desconfianza hacia el feminismo y seguia primando la visión de la militancia socialista como única vía para lograr la emancipación integral de todas las mujeres.

Mónica Urrestarazu, quien sí tenía contacto con las ideas feministas, lo cuenta de la siguiente manera:

Empecé a hablar con mis compañeras e introduje la cuestión de la doble o triple jornada-explotación-militancia como una suerte de explicación para poder desnaturalizar, o al menos cuestionar, eso que parecía como inamovible. Al principio me costó mucho convencerlas, pero enseguida me di cuenta de que si eliminaba el enunciado "en el feminismo se habla de..." e iba a los bifes, me entendian mejor. Y así fue. ${ }^{27}$

Pese a estas dificultades, hacia 1995 la llamada "cuestión de la mujer" ya tenía un lugar ganado dentro del partido. Sin embargo, el abordaje todavía era espasmódico. Se aceleraba en los meses en que se llevaban a cabo los ENM y luego volvía a retirarse de la agenda partidaria. Ese año la caracterización de los ENM comenzó a cambiar y pasaron a ser valorados en forma positiva y a reconocer que en muchos talleres se sostenían posiciones radicalizadas y claramente antigubernamentales. ${ }^{28}$ También la problemática del aborto comenzó a ocupar mayor espacio en la reflexión. Si bien el reclamo por este derecho tenía larga trayectoria en el partido, nunca había sido debatido en profundidad. Nora Biaggio, dirigenta del gremio docente, comenzó a perfilarse como una de las militantes en la que recaia la responsabilidad de abrir un proceso de organización partidaria hacia las mujeres.

El año1997 fue bisagra para la politica del partido hacia las mujeres por varios motivos. En primer lugar, retomaron la tradición de conformar comisiones de apoyo de esposas e hijos a determinadas luchas sindicales. Los casos más emblemáticos fueron los conflictos de los choferes de Transportes del Oeste (TDO) y de la editorial Atlántida. La organización

27. Entrevista a Mónica Urrestarazu, enero de 2021. Mónica comenzó a militar en el barrio de Parque Patricios a mediados de la década de 1990. En su juventud había militado en el PST donde se conectó con ideas del feminismo.

28. Virginia Villanueva, "El "Encuentro Nacional de Mujeres" se radicaliza", Prensa Obrera, 7 de noviembre de 1995. 
explícita de las mujeres habilitaba un proceso de politización y empoderamiento que, aun enmarcado en la legitimidad de los roles tradicionales, permitian fisurar el ámbito privado y restituir los sentidos sociales de la maternidad y las tareas de cuidado. Como recuerda Ileana Celotto:

La comisión de mujeres de Atlántida la conformamos justamente frente a la situación de un cierre de fábricas. Compañeras mujeres que en realidad nunca habian salido a hacer una actividad militante, no eran activistas, no eran delegadas, la mayoría ni siquiera trabajaba pero que después del paso por la comisión de mujeres, pasaron a ser otras. ${ }^{29}$

Fue precisamente esta caracterización la que comenzó a crear las condiciones para la construcción del Plenario Autoconvocado de Trabajadoras al año siguiente. Finalmente, en 1997, el PO determinó el inicio de un proceso de territorialización de su militancia que se plasmó en el objetivo de apertura de doscientos locales en todo el país en el marco de la promoción de una Asamblea Nacional de Trabajadores ocupados y desocupados para construir un plan de acción conjunto.

Como puede apreciarse, toda la política del partido en ese año creaba mejores condiciones para la participación de las mujeres. La territorialización de la militancia iba acompañada de una feminización que no podia ignorarse.

Ya a inicios de 1998 el PO comenzó a organizar a las mujeres de los barrios para la participación de las movilizaciones del 8 de marzo, jornada en la que hizo su presentación pública el PdT.

El PdT no fue concebido como una agrupación autónoma del partido, sino como fracción de mujeres del PO, con participación de independientes. Esto quiere decir que las mujeres podian sumarse sin ser del Partido Obrero, pero al hacerlo, aceptaban que la línea era definida por el partido.

Desde entonces, el PO profundizó la militancia territorial y en el año 2000 esa tarea se tradujo en la creación del Polo Obrero, denominado así justamente como proyección de un "polo" de concentración de trabajadores. Esa herramienta posibilitó un crecimiento inédito de las filas partidarias que tuvo impacto también en el frente de mujeres. Como habia ocurrido con la experiencia en las comisiones de esposas, la intervención entre las desocupadas permitía una reapropiación específica del programa del movimiento de mujeres posibilitando un proceso de politización con características propias.

29. Entrevista a Ileana Celotto, febrero de 2021. Comenzó su militancia en la Juventud de Política Obrera en 1973. Militó en diversos frentes. Actualmente es Secretaria General de la Asociación Gremial Docente de la UBA. 


\section{Algunas conclusiones}

En las últimas décadas del siglo XX los partidos de izquierda incorporaron, cada uno a su tiempo y con tonalidades propias, muchas de las demandas que venía sosteniendo el movimiento de mujeres y el feminismo en particular, cuyas presencias se tornaron patentes en los años 1980. En este artículo se buscó mostrar que con el final de la dictadura militar en 1983 el diálogo entre la izquierda partidaria y el feminismo se desarrolló atravesado por tensiones y desconfianzas, pero también por influencias recíprocas no siempre reconocidas como tales. Mirado de conjunto, la expansión del feminismo fue un fenómeno que abrió grietas y debates al interior de los partidos de izquierda. Si, inicialmente, es posible pensar, como lo hacian las feministas, que hicieran un uso instrumental de las demandas, en todos los casos, la propia experiencia fue transformando a las militantes que abrazaron las luchas con sinceridad y contribuyeron a democratizar sus organizaciones. A la inversa, la izquierda cumplió un rol fundamental en la circulación de las reivindicaciones de las mujeres en los sindicatos y en los barrios más pobres, lo que modificó la composición de clase del movimiento. Estas experiencias aún deben ser estudiadas en profundidad para establecer periodizaciones más precisas y dar cuenta de la variabilidad regional, descentrando las narrativas organizadas desde la militancia porteña. De esta primera exploración surgen numerosas preguntas y temáticas que organizan una agenda de investigación profusa y prometedora. En primer lugar, resta profundizar el trabajo desarrollado por cada partido y determinar sus derroteros en el tiempo. Analizar, por ejemplo, el abordaje que han hecho de distintas problemáticas tales como el lugar del trabajo doméstico, por la paridad en las instituciones, contra las violencias, las campañas por el aborto legal, entre otras que atravesaron al movimiento de mujeres en aquellos años. En otro plano, nos preguntamos por la especificidad de las militancias femeninas dentro de los partidos: las formas de reparto de cargos y de poder simbólico entre varones y mujeres; la existencia y problematización de las dobles y triples jornadas; de las violencias entre militantes, de la homofobia, entre muchas otras cuestiones relacionadas con la experiencia personal de las militancias de izquierdas. De conjunto, tenemos por delante una línea de investigación que permitirá entender los recovecos de un recorrido conflictivo, contradictorio, con muchas idas y vueltas, pero decisivo para permitir la democratización de las estructuras partidarias, revolucionar las militancias y ampliar las nociones actuales de lo que entendemos por socialismo. 


\section{Referencias}

Alma, A. y P. Lorenzo (2009). Mujeres que se encuentran. Una recuperación histórica de los Encuentros Nacionales de Mujeres en Argentina (19862005). Feminaria.

Bellucci, M. (2014). Historia de una desobediencia. Aborto y feminismo. Capital Intelectual.

- (2020). Orgullo, Carlos Jáuregui. Una biografia politica. Crítica.

Carrasco, C. y M. Petit (1979), Mujeres trabajadoras y marxismo, pp. 250-253. Disponible en http://phl.bibliotecaleontrotsky.org/arquivo/ mv02nee/mv02nee-16cp.pdf.

Casola, N. (2014). Con "m" de mamá: las militantes comunistas y la Unión de Mujeres Argentinas durante la segunda mitad del siglo XX, Amnis, $\mathrm{n}^{\circ}$ 13. https://journals.openedition.org/amnis/2093.

Felitti, K. (2010). Sexualidad y reproducción en la agenda feminista de la segunda ola en la Argentina (1970-1986), Estudios Sociológicos, XXVIII, 84.

Franco M. (2009). El exilio como espacio de transformaciones de género. En AA.VV., De minifaldas, militancias y revoluciones. Exploraciones sobre los 70 en Argentina. Luxemburg.

Grammático K. (2019). Los años de la dictadura. En M. Tarducci, C. Trebisacce y K. Grammático, Cuando el feminismo era mala palabra. Algunas experiencias del feminismo porteño. Espacio.

Seminara L. y C. Viano (2009). Las dos verónicas y los múltiples senderos de la militancia: de las organizaciones revolucionarias en los años 70 al feminismo. En AA.VV., De minifaldas, militancias y revoluciones. Exploraciones sobre los 70 en Argentina. Luxemburg.

Tarducci, M. (2019). Los años 80. En M. Tarducci, C. Trebisacce y K. Grammático, Cuando el feminismo era mala palabra. Algunas experiencias del feminismo porteño. Espacio.

Trebisacce, C. (2019). Los años setenta. En M. Tarducci, C. Trebisacce y K. Grammático, Cuando el feminismo era mala palabra. Algunas experiencias del feminismo porteño. Espacio.

- y M. Mangiantini (2015). Feminismo, diversidad sexual y relaciones sexoafectivas disidentes. Apuestas y tensiones en el Partido Socialista de los Trabajadores (PST) entre 1971 y 1975, Archivos de Historia del Movimiento Obrero y la Izquierda, 4, 7, 101-120.

Valobra, A. (2005). La UMA en marcha. El Partido Comunista Argentino y las tradiciones y estrategias de movilización social en el primer gobierno peronista : el caso de la Unión de Mujeres Argentinas (UMA), Canadian Journal of Latin American and Caribbean Studies, 30, 60.

Vasallo, M. (2009). Militancia y transgresión. En AA.VV., De minifaldas, militancias y revoluciones. Exploraciones sobre los 70 en Argentina. Luxemburg.

Viano, C. (2014). Voces (des)encontradas en los Encuentros Nacionales de Mujeres en Argentina. Paginas, 6 (11), 49-68. https: / / doi.org/ 10.35305/ rp.v6i11.29 